\title{
Por uma pesquisa imaginativa na formação do jovem pesquisador
}

Rafael Vicente de Moraes ${ }^{1}$

MORAES, R.V. In defense of imaginative research programs in the education of young researchers. Interface Comunic., Saúde, Educ., v.11, n.21, p.105-18, jan/abr 2007.

This article discusses certain issues related with science and its internal ramifications from the viewpoint of capitalist production, based on a rationale oriented fundamentally by the combination of capitalist globalization and the monopolization of technical and scientific knowledge. Man, having become an object of himself, is incapable of reflecting on himself and his practices, even though he may have developed refined mechanisms for understanding reality. The debate reveals the possibility of thinking about certain aspects of the training of young researchers in the field of the humanities, such as the lack of discussion of the boundaries and reach of scientific exercise. Thus, one suggests the idea of imaginative research as a means to acquisition of knowledge, reflection and theoretical clarification.

KEY WORDS: science. construction of the knowledge. imaginative research. research personnel. domains of science.

Discutem-se algumas questões concernentes à ciência e seus desdobramentos internos, sob o modo de produção capitalista, tendo como eixo central uma racionalidade orientada fundamentalmente por combinar a mundialização capitalista à monopolização dos conhecimentos técnicos e científicos. O homem, tornado objeto de si mesmo, é incapaz de refletir sobre si próprio e sobre sua prática, ainda que tenha desenvolvido mecanismos refinados para conhecer a realidade. $\mathrm{O}$ debate abre perspectivas para se pensar determinados aspectos da formação do jovem pesquisador, na área de ciências humanas, como a ausência de uma discussão acerca dos limites e alcances do exercício científico. Nesse sentido, sugere-se a idéia de pesquisa imaginativa, enquanto um modo de conhecimento, reflexão e clarificação teórica.

PALAVRAS-CHAVE: ciência. construção do conhecimento. pesquisa imaginativa. pesquisadores. domínios científicos.

\footnotetext{
${ }^{1}$ Professor, Faculdade Reunida de IIha Solteira, SP; Faculdade Aldete Maria Alves (FAMA), Iturama, MG. <ravimo@marilia.unesp.br>
} 
O racionalismo moderno creditou à ciência ocidental um papel libertador e emancipador. Não obstante, a ciência dita moderna tornou-se, sob o manto do modo de produção capitalista, a concretização de um grande projeto de racionalidade e dominação, que engendra a natureza, o univer so social e concepções de mundo historicamente forjadas. Coube como desígnio maior à ciência, por meio de observações e experimentos (Pessanha, 1993), desenvolver técnicas de manipulação para desvelar as leis universais presentes no universo em todas as suas esferas, desde os movimentos planetários até as partículas subatômicas, e assim fundar o reinado da racionalidade.

A ciência moderna fez da busca de leis gerais sua meta prioritária. Nesse particular, a Física e a Matemática dispunham dos métodos de proceder e de se atingir o rigor e o objetivismo. A apreensão da realidade passou a estar subsumida pela mensuração.

A ciência tem uma história tardia e sinuosa (Paty, 1999). É um conceito complexo que implica uma gama de fundamentos epistêmicos. A ciência é um esforço coletivo (Durkheim, 1969) que não se constrói em um contexto intemporal, nem pelo simples fato de que seu objeto/sujeito exista, cabendo ao homem o emprego de suas faculdades para conhecê-lo. Tampouco é um compêndio de conhecimentos sistematicamente elaborados. Entretanto, parece desenhar seu locus no mundo atual calcado em uma utilidade imediata, restringindo-se, cada vez mais, ao âmbito da técnica.

No transcorrer dos últimos séculos, os avanços da ciência permitiram o desenvolvimento de incontáveis formas de tecnologia, por meio das quais alargaram o domínio do homem sobre a natureza e, por isso mesmo, requerem uma análise que sublinhe, não só, os aspectos positivos, mas também os negativos. Quer dizer, a experiência humana é enriquecida com possibilidades de melhorias na qualidade de vida, entretanto, sua apropriação é "dádiva" de poucos. Nesse quadro, as conseqüências do avanço científico para as diversas classes e camadas da população constituem um dos pilares da crítica à ciência. Para Omnès (1996, p.257), “[...] apesar dessa confiança quase cega, a fé que podemos ter na ciência está ligada, sobretudo, a essa grandeza de triunfar aceitando a total vulnerabilidade de um guerreiro nu na arena".

A ciência é generalizante e territorializa, não raras vezes, desconsiderando a história peculiar de cada grupo ou comunidade humana. Autores como Dussel (1993), Said (1990), Santos (1999) demonstram que esse processo está ancorado no iluminismo ocidental, notadamente o eixo Europa-Estados Unidos, por meio do qual se (re)produz a hegemonia desse modus cultural, invisibilizando, em seu discurso, toda materialização de práticas e conflitos entre grupos, para legitimar seu domínio sobre sistemas locais de cultura, seja desvalorizando-os, seja incorporando-os com vistas à pretensa idéia de "universalidade da ciência"2.

Quando a ciência e seus projetos se compartimentalizam, a atividade humana intelectiva e as idéias são instrumentalizadas, isso torna o homem objeto de si mesmo. As idéias são circunscritas em esquemas de ação. Segundo Buber (1962, p.63, tradução nossa): “O problema do homem se reduziu à pergunta sobre a natureza do homem, que ganhou novo

\author{
2 O pensamento \\ filosófico iluminista \\ fundamentou a \\ existência de um \\ sujeito universal e \\ autônomo, a saber: \\ homem europeu, \\ branco e burguês. \\ Essa representação \\ instituiu, entre outras \\ questões, a dicotomia \\ das relações de poder \\ entre homens e \\ mulheres. O plano da \\ natureza humana \\ delimitou, a partir daí, \\ a subordinação e \\ inferioridade para \\ explicar as diferenças \\ entre homens e \\ mulheres. Destacamos \\ a "questão da \\ mulher", trazida para \\ o interior das \\ instituições \\ acadêmicas na década \\ de 1970; os Estudos \\ Feministas gestaram \\ outra forma de \\ enfoque da opressão \\ da mulher enquanto \\ sexo, as lacunas e \\ compreensões \\ distorcidas por parte \\ da ciência (Harding, \\ 1986). Portanto, uma \\ nova consciência \\ social, que denunciava \\ as desigualdades entre \\ as pessoas em virtude \\ do sexo. Entre outros \\ desdobramentos desse \\ processo, assistiu-se a \\ emergência de novos \\ atores e movimentos \\ sociais, como as \\ minorias sexuais - \\ gays e lésbicas -, \\ estudos sobre o negro \\ etc., que acabaram \\ constituindo \\ instigantes campos \\ investigativos que \\ passaram a reescrever \\ a história com base \\ em suas próprias \\ lentes.
}


${ }^{3}$ Por exemplo, o Projeto Genoma, que é um vasto projeto científico, cujo objetivo é mapear completamente a base genética da espécie humana, o que, evidentemente, gera questões éticas, morais e comerciais (Wan-ho, 2001).

${ }^{4} \mathrm{O}$ ano de 1543 assinala uma data significativa para a ciência moderna, pois nela foram publicados o De Revolutionibus Orbium Coelestium, de Nicolau Copérnico (1473-1543), e o

De Humani Corporis Fabrica, de Andreas Vesalius (1514-

1564). O primeiro reformulou os pressupostos da Astronomia, e o outro, da Anatomia.

${ }^{5}$ Atualmente, a crença em princípios universais e em idéias reguladoras da vida humana foi profundamente abalada. Para Santos (1999, p.144), vivese "uma época em que é muito difícil ser-se linear. Porque estamos numa fase de revisão radical do paradigma epistemológico da ciência moderna, é bem possível que seja, sobretudo, o olhar que está a mudar". Nesse sentido, Heisenberg (1989), que faz parte da geração de físicos que defendem a relatividade da ciência unidisciplinar, admite 0 questionamento aberto da especificidade do mundo físico e de suas leis.

${ }^{6}$ Para Moscovici (1995), essa redução drástica e

deformadora impede de se perceberem, nos fenômenos psicossociais, as dissonâncias em todo seu significado e amplitude. significado, sobretudo, prático". A ciência e o exercício científico degeneramse em ofício de cariz utilitário. Nessa direção, aponta Castro (1978, p.7): “O pesquisador opera como se não tivesse outro objetivo que não decifrar a realidade. Mas seu sucesso, em última análise, será dado pela utilidade prática que algum dia possa ter essa maneira peculiar de decifrar o mundo real".

Hoje, tem-se a sensação de que a produção técnico-científica atinge escalas elevadas, excedendo a própria capacidade humana para compreendê-la em suas reais dimensões e significados. Observemos as pesquisas na medicina, biologia molecular, genética ${ }^{3}$. Refletir acerca do lugar da ciência no modo de produção capitalista implica considerar que a ciência, no século XX, não se aplica/materializa somente por meio de técnicas, mas é capaz de forjar as próprias coisas como ações que nelas incidem. A realidade social e natural é, a um só tempo, dominada e produzida, tendo como pano de fundo uma racionalidade orientada fundamentalmente por combinar a mundialização capitalista com a monopolização de conhecimentos técnicos e científicos.

Nesse sentido: "O pensamento científico é, ainda, incapaz de se pensar, de pensar sua própria ambivalência e sua própria aventura" (Morin, 2001, p.11). O homem é incapaz de pensar a si próprio, ainda que tenha desenvolvido os mais refinados mecanismos para desvelar o mundo. Falta à sociedade e, mesmo, ao quadro institucional acadêmico, uma compreensão mais abrangente do "que é ciência", como está estruturada, seu enraizamento sociocultural, os valores axiológicos nela imiscuídos, ou seja, problematizar acerca de suas várias esferas, tendo, no horizonte analítico, as transformações do homem e as transformações do mundo, que, em tempos de globalização, ocorrem em um ritmo vertiginoso. Tais questões deveriam estar no horizonte da formação do jovem pesquisador, abrindo, assim, caminhos para novas aquisições intelectuais.

\section{A atividade de pesquisa: contornos e nuanças}

Desde o final da Idade Média ${ }^{4}$, em decorrência da expansão da ciência, a questão do método começou a adquirir importantes contornos, sobretudo, com o racionalismo cartesiano, calcado em princípios gerais relativos às ciências naturais e às ciências matemáticas enquanto único caminho para se chegar à verdade 5 . No ocidente, o referencial cartesiano introduziu, na existência humana, a dicotomização ${ }^{6}$. Morin $(2000$, p.26) denomina esse processo de 'dissociação': alma/corpo; finalidade/causalidade; indivíduo/ coletivo; sujeito/objeto, e, em si, todas são excludentes.

Esse dualismo pernicioso entre a esfera social e a individual encontra seus representantes entre sociólogos e psicólogos, respectivamente. No mundo social, tem-se o peso do grupo enquanto matriz explicativa das estruturas, do poder e das negociações, anulando as singularidades do indivíduo por meio do consenso. No outro, o da especificidade individual, os comportamentos e valores são tidos como resultados de processos subjetivos, que envolvem motivações, inter esses e necessidades de cada sujeito. Tanto num quanto noutro ocorre uma redução drástica dos fenômenos e das experiências psicossociais, ou melhor, entre o coletivo e o individual, entre socialização e 
individualização. Na verdade, é negado o eixo conflitivo das referidas dimensões, produzindo uma idéia engessada e distorcida da sociedade e do indivíduo.

Os cânones da "ciência clássica" pautavam-se na idéia de que a complexidade do mundo dos fenômenos devia ser compreendida com base em leis gerais. Pensava-se a questão de "procurar o verdadeiro método para chegar ao conhecimento de todas as coisas" (Descartes, 1983, p.36-7). Esse problema continua a ser discutido pelas teorias do conhecimento, pois é fundamental o papel do método no processo de construção do conhecimento, como um instrumento empregado pelo sujeito para apreender a realidade. $A$ moderna racionalidade científica tem uma referência explícita na obra de Descartes (1983, p.63): ${ }^{7}$

[...] conhecendo a força e as ações do fogo, da água, do ar, dos astros, dos céus e de todos os outros corpos que nos cercam, tão distintamente como conhecemos os diversos misteres de nossos artífices, poderíamos empregálos da mesma maneira em todos os usos para as quais são próprios, e assim nos tornar como que senhores e possuidores da natureza.

O método das ciências naturais, a que se refere Descartes, não deve nos orientar para uma simples averiguação naturalística de grandes sistemas, pois sinaliza, mesmo sem desconsiderar os pressupostos já elaborados, para uma postura transformadora capaz de articular o domínio da natureza pelo homem com a nova ciência. Doravante, o método cartesiano, ao radicalizar o objeto na ciência, é um gesto inaugural na criação de um discurso rigoroso e, do ponto de vista científico, universalmente válido. A experiência humana, captada por meio dos sentidos, funda-se no esforço de ser completada pela passagem da percepção sensível para o refletido. $O$ ato de conhecimento se inscreve na ação do sujeito, nas experiências concretas, nas inúmeras intenções que procuram as mais diver sas realizações, por isso mesmo, remete a esse mundo, significando um modo de interpretá-lo. Como toda intencionalidade, tal empreendimento entre o pretender e o concretizar abriga grande carga de tensão, mesmo quando objetivado.

A constituição do pensamento repousa não só nas relações objetivas princípios, leis, normas, ordens - universalmente válidas, mas também em estruturas de cada sujeito, nas quais o homem cria a si mesmo, não quando se parte apenas do sujeito isolado, porém de sua pluralidade. O homem, em sua ação efetiva, dá forma à natureza e a si mesmo, diferentemente do animal que se encontra envolto na estrutura fixa de leis naturais, sendo determinado por elas; o homem transpõe essa determinação, porque possui um leque de possibilidades no qual pode desenvolver suas atividades. Não apenas age, como os outros animais, porém interpreta sua ação que, na verdade, é resultado de uma inter pretação.

As construções teóricas derivam de um quadro de hipóteses, idéias e sistematizações prévias forjadas histórica e coletivamente. Tal sistematização é o alicerce para a ampliação do conhecimento sob novas configurações. O caminho para isso chama-se método. Segundo Chauí (1994, p.354):

“Methodos significa uma investigação que segue o modo ou uma maneira
7 René Descartes (1596-1650), autor de Discurso do Método, publicado originalmente em 1637. 
planejada e determinada para conhecer alguma coisa; procedimento racional para o conhecimento seguindo um percurso fixado". Essa idéia é completada por Morin (2001, p.335-6) “[...] método é a praxis fenomenal, subjetiva, concreta, que precisa de geratividade paradigmática/teórica". As coisas e as relações entre elas nem sempre estão presentes e manifestas. Porque, se assim o fosse, o entendimento humano seria reflexo preciso da realidade imediata, e os fatos, redutíveis a dados empíricos, como prega a atitude positivista, deixando escapar a dimensão histórico-social da ação humana. As falas, os fenômenos, os dados não falam por si mesmos. Ao serem identificados, necessitam ser analisados, pois o real se deixa transparecer apenas em grau epidérmico, sendo imprescindível ir além da imediaticidade para abarcar as conexões internas, os vínculos entre a parte e o todo, e viceversa. A realidade e seus processos intrínsecos só são conhecidos quando (re)criados no pensamento, adquirindo inúmeros sentidos. A faculdade de conhecer não prescinde do trabalho e da engenhosidade intelectual com os quais há uma apropriação do mundo pelo pensamento, muito embora não seja suficiente para transformá-lo.
${ }^{8}$ A esse respeito, ver a entrevista de Chomsky apud Moscovici (1995, p.15): "Jamais alguém tornará criativo um físico ou um biólogo, dizendoIhe: eis aqui os métodos, experimente num organismo. Fazem isso os que não sabem o que dar para os estudantes fazerem. É uma confissão de fracasso. Espera-se de um cientista que ele descubra novos princípios, novas teorias, novos métodos de verificação [...] I sso não se aprende com um método".

\begin{abstract}
A finalidade imediata da atividade teórica é elaborar ou transformar idealmente, e não realmente, para obter como produtos teorias que expliquem uma realidade presente ou modelos que prefigurem uma realidade futura. A atividade teórica proporciona um conhecimento indispensável para transformar a realidade. [...] mas não transforma em si a realidade, a não ser quando apropriada pela consciência individual e coletiva, e então transforma as idéias em ações. (Vásquez, 1968, p.203)
\end{abstract}

Em largos traços, a atividade de pesquisa necessita aprender a aproximar-se de seu objeto, buscando identificar suas manifestações intrínsecas. Desde outrora, denomina-se methodos, ou seja, o caminho que nos leva aos meandros das coisas e suas relações. O como/porquê ocorre um fenômeno e em qual(is) campo(s) se circunscreve é um modo primário de aproximação do real que resulta na criação de problemas. Estamos falando de um método, nas ciências humanas, não fetichizado de interrogação, e não da resolução prática, imediata e experimental ${ }^{8}$ de problemas. Embora isso provoque discordâncias - e uma certa apreensão no autor - afirmamos que tal problema é de escolha pessoal, o ethos do trabalho. Essa é sua especificidade intrínseca.

A atividade científica funda-se em uma gama de questões previamente forjadas, com as quais a pesquisa criativa e o pesquisador enfrentam seus questionamentos, e é sob tais condicionantes que o pesquisador conduz seu empreendimento. A ciência não dá conta de abarcar as múltiplas faces de uma realidade dinâmica de forma total, pois está condicionada por estruturas históricas e sociais, processos reprodutivos e, também, pela intervenção humana, que não se curva aos ditames das circunstâncias encontradas (Goldmann, 1967; Vásquez, 1968). Apreendido somente por aproximação, o real, segundo Lênin apud Lukács (1967), é muito mais rico e complexo do que qualquer teoria, qualquer pensamento que se possa ter acerca dele. A atividade do pensamento tende a fragmentá-lo. 
No mundo atual, a pesquisa acadêmica parece transformar-se na criação de fórmulas que permitam manipular a realidade com acentuado reducionismo. A pesquisa imaginativa, pelo contrário, deve se nutrir no sentido de captar os múltiplos encadeamentos de um mesmo objeto, num esforço constante para manter-se nessa unidade integral, não se restringindo a mera busca do conhecimento. Ela se esforça para abrigar as várias correntes de pensamento, sem desconsiderar sua dimensão colaborativa/conflitiva. A pesquisa é um processo cumulativo, por meio do qual o exercício reflexivo é expresso e ampliado, onde o conhecimento científico assume, a um só tempo, sua dimensão humana e histórica. A atividade do sujeito-pesquisador é entendida em dois sentidos: individual e social, exercida não só na escolha, mas nas transformações por ele operadas.

\begin{abstract}
Se a natureza e os frutos do acaso são passíveis de interpretação, de tradução em palavras comuns, no vocabulário absolutamente artificial que construímos a partir de vários sons e rabiscos, então talvez esses sons e rabiscos permitam, em troca, a construção de um acaso ecoado e uma natureza espelhada, um mundo paralelo de palavras e imagens mediante o qual podemos reconhecer a experiência do mundo que chamamos real. (Manguel, 2001, p.23)
\end{abstract}

Busca-se conferir significações às experiências humanas e, nesse processo, a tessitura de nossas reflexões é elaborada com base em um emaranhado de idéias, experiências coletivas e individuais, nas relações com outros homens e com a natureza, que criam um campo de possibilidades a ser investigado. 0 terreno no qual germinam as construções teóricas, desde seu limiar, é per passado pela totalidade das relações sociais, ideológicas, culturais e econômicas.

Assim sendo, ao invés de ar bitrariamente destacarmos algum desses elementos como variáveis independentes, por exemplo, o social ou o econômico, e cairmos em um sentido unilateral, acentuamos que todas as variáveis dependem, por seu turno, do conjunto das relações humanas. 0 exercício da pesquisa implica descobrir, formular e intervir. As concepções de mundo dos atores sociais envolvidos e as do pesquisador encontram-se latentes em todo o processo de conhecimento, desde a escolha do objeto até o resultado do estudo.

Weber (1992), ao analisar o método das ciências históricas e sociais ${ }^{9}$ acredita ser impossível eliminar as pré-noções ou os juízos de valor no trabalho investigativo, daí a necessidade de "integrá-los conscientemente na ciência e fazer deles instrumentos úteis na investigação da verdade objetiva" (Goldmann, 1967, p.34). As opiniões e os valores do pesquisador, estando fincados em um substrato coletivo que compõe sua subjetividade, são aspectos constitutivos da atividade intelectual. Pois:

[...] a ilusão começa quando imaginamos que, de um lado, há os fatos e, de outro, a teoria e quando dissimulamos a posição em razão da qual esta divisão aparece. Somos então forçados a descrever o movimento do conhecimento como se nele não tomássemos parte e fixar sua origem de um lado ou do outro. (Lefort, 1979, p.256)
${ }^{9}$ As ciências sociais emergiram enquanto disciplinas institucionalizadas, no cenário das ciências, no final do século XIX. 
Pressupondo que o entendimento do real transpõe os fenômenos percebidos pelos sentidos, incorporar, no enfoque, as dimensões objetiva e subjetiva, o objeto e sua carga de significados, a gama de valores do cientista, é assumir uma postura de análise desafiadora atravessada pelo aspecto conflitivo. Isso não significa, no entanto, que determinada teoria possa oferecer uma compreensão completa acerca da realidade, porque:

\begin{abstract}
Envolver uma teoria com o manto da verdade é atribuir-se uma característica não realizável historicamente. Nada mais prejudicial ao processo científico que o apego a enunciados evidentes, não discutíveis. Somente na teoria se pode dizer que a ciência é a interpretação verdadeira da realidade, porque, na prática, toda interpretação realiza apenas uma versão historicamente possível. (Demo, 1981, p.25)
\end{abstract}

O acento dado ao objeto tem condicionantes históricos - as correntes de pensamento vigentes na sociedade e a posição social do cientista Lowy (1985); Lukács (1974). Apoiando-se num instrumental teórico-metodológico, a fim de se aproximar da realidade, é preciso a crítica permanente do objeto das ciências humanas - que é amplo e inacabado - e das condições subjetivas pesquisador.

\section{Dos riscos do empirismo}

No domínio das ciências naturais que estudam os fenômenos químicos, físicos e biológicos, a ocorrência destes não depende necessariamente da intervenção humana. Por exemplo, na química, a lei de Proust, segundo a qual a composição do óxido de mercúrio tem sempre os mesmos elementos oxigênio e mercúrio - distribuídos na mesma proporção em quaisquer lugares ou circunstâncias históricas. O mesmo ocorre com a lei de gravitação universal de Isaac Newton, pois nenhum corpo do universo deixa de ser submetido a ela.

Estando as ciências naturais calcadas na exatidão e na certeza, sua propalada objetividade ventilou a possibilidade de estender o racionalismo científico e empírico para a esfera da vida social. Desse modo, para Durkheim $(1969,1983)^{10}$, as sociedades deveriam ser analisadas por meio do método positivo, baseado na observação e na experimentação, da forma como se dava nas ciências naturais. Segundo Durkheim apud Moya (1970, p.230):

As ciências humanas serão constituídas a partir da imitação das ciências naturais, já que o homem é só uma parte da natureza. No mundo não há dois mundos: um que derive da observação científica e outro que escape a ela; o universo é uno e uno também é o método de que nos servimos para explorá-lo em todas suas partes [...] Posto que se há demonstrado que o método positivo é o único que permite conhecer o mundo inorgânico, se deduz que é também o único que convém ao mundo humano.

Para Chizzotti (2000), a predominância da visão positivista na pesquisa em Ciências Humanas, caracterizada pelas estruturas imutáveis das relações, pela 
observação sistemática enquanto base da constituição do saber esteve presente no cenário investigativo até a década de 1970. A partir daí, novas orientações filosóficas e sociológicas ganharam força, tratando de expor os limites do positivismo, de sua pretensa neutralidade científica e das relações existentes entre conhecimento científico, configurações sociais e reprodução social. Passou-se a ressaltar a complexidade e as contradições nos fenômenos e a presença criadora dos agentes sociais, por meio dos quais o homem experimenta incontáveis meios de aproximação, mediação, interlocução com o empírico.

Enquanto crítica contundente, a atividade de pesquisa adquire um esvaziamento de suas dimensões, por exemplo, quando identificada à empiricidade, ou seja, a condição do pesquisador tão só ouvir, transcrever, manipular, mensurar os dados coletados por meio de gráficos, tabelas, números, questionários ${ }^{11}$. É o elemento empírico que fala por si só. Para Durkheim (1983, p.74):

Não podemos cair na tentação de ultrapassar os fatos, quer para explicálos, quer para explicar o seu curso. [...] Se eles são inteiramente inteligíveis, então bastam tanto à ciência, porque, neste caso, não há motivo para procurar fora deles próprios a sua razão de ser; e à prática, porque o seu valor útil é uma das razões.

Os dados referentes a uma dada realidade, desde que devidamente coletados e manipulados mediante sofisticados instrumentos de análise, semelhantes aos utilizados nas ciências naturais, buscam livrar todo o tipo de valor, preconceito ou opinião político-ideológica da parte do investigador, expressando-se por meio de uma linguagem neutra (Durkheim, 1983). Em linhas gerais, o positivismo busca as regularidades e explicações causais e defende que a sociedade e os grupos são regulados por leis naturais que atravessam a esfera social econômica, eliminando, assim, o pluralismo da sociedade, as lutas e contradições de classe (Durkheim, 1969, 1983).

A realidade circunscreve-se, apenas, ao observado e quantificado e isso significa, naturalmente, que tem recebido muitas críticas (Adorno \& Horkheimer, 1979; Dilthey, 1956; Weber, 1992). A crítica ao empirismo aponta:

\footnotetext{
A maldição das ciências humanas, talvez, seja o fato de abordarem um objeto que fala. [...] Não basta que o sociólogo esteja à escuta dos sujeitos, faça a gravação fiel das informações e razões fornecidas por estes, para justificar a conduta deles e, até mesmo, as razões que propõem: ao proceder dessa forma, corre o risco de substituir pura e simplesmente suas próprias prenoções pelas prenoções dos que ele estuda, ou por um misto falsamente erudito e falsamente objetivo da sociologia espontânea do 'cientista' e da sociologia espontânea de seu objeto. (Bourdieu et al., 2002, p.50, grifo dos autores)
}

Os autores valorizam a fala do sujeito como expressão das condições de existência e, em especial, para Bourdieu, a palavra é o símbolo da

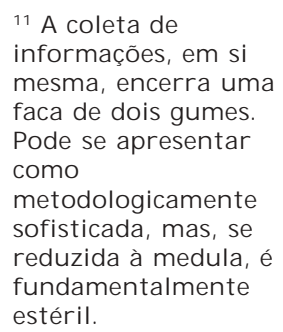


12 Para Lukács (1967), é precisamente esse conjunto que reúne os membros de um grupo, comunidade ou classe social e permite a vinculação do pensamento individual nas tramas sociais, ou seja, a consciência do sujeito expressa a consciência coletiva. comunicação, pois ela representa o pensamento. A fala, ao representar grupos determinados, em condições históricas, sociais e culturais específicas, revela um sistema de valores e normas que define o campo de expressão das relações sociais.

Os autores criticam o empirismo exacerbado que conduz à submissão pura aos fatos e fenômenos como único imperativo, não se transpondo os dados aparentes, portanto, inexiste uma compreensão mais abrangente de seus significados. Trava-se um embate contra esse tipo de empirismo que acredita apreender as significações das estruturas e dos atores como se o real se revelasse pelos dados, além de ser responsável por retirar a subjetividade do pesquisador. Quanto ao enfoque metodológico, acrescenta Demo (2000, p.19): "A tendência de reduzir à sua expressão empírica é facilmente compreensível, porque é a mais manipulável diante da expectativa metodológica dominante. É tanto mais tratável cientificamente, aquilo que é mensurável, experimentável, observável".

\section{Por uma pesquisa imaginativa}

A pesquisa imaginativa deve estar calcada em duas esferas inextrincavelmente ligadas: a discursiva e a analítica. Isso implica considerar - por que não dialogar com - referenciais inter pretativos distintos e identificar os condicionantes históricos e ideológicos nas concepções teórico-metodológicas. Não somente teorias e técnicas investigativas têm papel fulcral, mas o potencial criativo do pesquisador também adquire envergadura, no sentido de perceber as múltiplas relações, nem sempre perenes, que cercam a realidade.

A criatividade na pesquisa significa aprendizado, motivação, acuidade, comunicação. É fundamentalmente exploratória e inovadora, porque não só dilata, mas empreende novos conceitos. O universo da produção do conhecimento é constituído de sujeitos munidos de experiências, pensamentos, sensações ${ }^{12}$, estando em permanente contato com ele, e permitem, sob a urdidura dessa relação, compreendê-lo em sua complexidade, reunindo, ao mesmo instante, ferramentas conceituais que possibilitam a criação de algo novo.

A atividade de pesquisa demanda certa flexibilidade, diálogo com outros investigadores e/ ou grupos, além dos atores sociais envolvidos com vistas ao escopo investigativo. Muitos outros aspectos se interpõem nas preocupações do investigador. Schnitman (1996, p.13) fala em simetrias e assimetrias:

\footnotetext{
O mundo [...] é rico em evoluções imprevisíveis, cheio de formas complexas e fluxos turbulentos, caracterizados por relações não-lineares entre causas e efeito, e fraturado entre escalas múltiplas de diferente magnitude. [...] A ordem pode ser conceituada não como uma condição totalizadora, mas como uma duplicação de simetrias e assimetrias [...].
}

O processo de pesquisa, como o entendemos, é um conjunto de reflexões articuladas em torno de inúmeras questões: domínio de técnicas (trabalho de campo, entrevistas, questionários, sondagem, pesquisa bibliográfica etc.) que 
se relacionam ao exercício de sistematização, análise, síntese, escrita. Longe de ser algo linear, o processo de pesquisa compreende um exercício reflexivo lento de observações, inter-relações que conduzem o pesquisador a possíveis redimensionamentos das hipóteses inicialmente forjadas.

A pesquisa imaginativa é uma recriação que carrega consigo os traços do autor, mas não perde de vista a complexidade de seu objeto, suas especificidades enquanto parâmetros intrínsecos à dimensão de sua cientificidade. Diferentemente da lógica positivista, que procurava um conjunto de leis constantes e invariáveis da estrutura social, a perspectiva dialética admite que a compreensão da realidade está alicerçada no conflito e na contradição, enquanto princípios atuantes capazes de elucidar a transformação. A consciência é concebida como produto social da ação e da necessidade humanas em relação à natureza e aos outros homens. Esse esforço de entendimento da totalidade conduz o pesquisador a:

Apreender os fenômenos em sua auto-relação e hetero-relação, em suas relações com a multiplicidade de seus próprios ângulos e de seus aspectos intercondicionados, em seu movimento e desenvolvimento, em sua multiplicidade e condicionamento recíproco com outros fenômenos ou grupo de fenômenos. (Joja, 1965, p.55)

No cerne das práticas e discursos teóricos acerca da pesquisa - onde a universidade é o local privilegiado - o conhecimento é algo a ser construído. Assim entendido, o conhecimento é flutuante, gelatinoso, estando em constantes transformações. A construção do conhecimento não se circunscreve a um montante de informações e dados respaldados em uma teoria explicativa, pois o sujeito é atuante nesse processo na medida em que redimensiona os fenômenos, dando-Ihes significados.

O objeto, por sua vez, não é algo inerte, pelo contrário, está carregado de significados que a atividade humana Ihe dá. O pesquisador, ao trabalhar com a experiência cotidiana - as práticas, os discursos, as condutas criadoras, os estados mentais, as idéias -, não deve tomá-la enquanto reflexo crítico da realidade, sendo mister transpor as manifestações imediatas. Destaca-se que alguns teóricos (Goldmann, 1967; Lukács, 1967) não aderem totalmente ao racionalismo corrente, que considera a razão o único fundamento na construção do saber, e a experiência cotidiana humana como falseadora na busca da ciência social concreta. Os autores supracitados assumem uma posição de "relatividade" diante dos elementos racionais e subjetivos.

Nossos conhecimentos são apenas aproximação da plenitude da realidade, e por isso mesmo são sempre relativos; na medida, entretanto, em que representam a aproximação efetiva da realidade objetiva, que existe independentemente de nossa consciência, são sempre absolutos. O caráter ao mesmo tempo absoluto e relativo da consciência forma uma unidade dialética indivisível. (Lukács, 1967, p.233)

O conhecimento, longe de ser reflexo naturalizado da realidade, abriga nervuras discursivas e ideologicamente construídas e, por isso mesmo, todo 
saber é situado dentro de opções teóricas e metodológicas realizadas pelo investigador.

Buscamos, até o momento, o distendimento da rede de relações que definem e combinam a presença mesma do indivíduo no grupo em que vive. Isso permite afirmar que a obra do intelectual, do artista não reflete necessariamente o grupo a que pertence, porém nasce de uma malha de influências que a atravessa: a tradição de seus precursores, talvez até mais que as próprias condições históricas em que está envolto, e acaba expressando dilemas que ainda não se encontram nítidos para seus contemporâneos.

Ao propor um caminho tortuoso sem transposições conceituais imediatas, a pesquisa imaginativa exige do pesquisador uma força autônoma, freqüentemente em reconstrução, rumo a processos em que, ao invés de se estabelecer a linearidade dos fenômenos, ambiciona, não sem correr riscos, o estímulo ao debate. Todos sabem que o "conhecimento profundo e verdadeiro do mundo" tem, nas lentes da ciência institucionalizada, seu instrumento reconhecidamente autorizado. Contra a hipoteca da razão que sobrecarrega a atividade científica, a pesquisa imaginativa não exaure as possibilidades de entendimento da realidade, mas, nem por isso, deixa-se de se identificar os aspectos do objeto que interagem com as predisposições do pesquisador.

É uma forma de intervenção na realidade que não se orienta tão-só por questões pré-fabricadas travestidas num discurso inovador. Nesse ponto gravita nosso interesse, ao estabelecer o convite à manifestação e a uma certa liberdade interpretativa que mais sugere do que propriamente estabelece uma formulação rigorosa capaz de registrar a presença de determinado fenômeno. Não obstante, a idéia de pesquisa imaginativa está dotada de organicidade mínima, embora esteja em gestação.

A pesquisa imaginativa pressupõe a ruptura de esquemas e modelos explicativos e aceita a efemeridade desses mesmos modelos e a constante necessidade de releitura não só de obras próximas, mas no interior de uma mesma obra. Essa representação discursiva transborda a estrutura da pesquisa científica propriamente dita e oferece ao homem a possibilidade de autonomia do pensamento e da ação.

\section{Considerações finais}

O capitalismo hodierno é marcado pelo fracionamento das esferas e atividades humanas. A ciência - ainda que participe ativamente da sociedade, mesmo com sua carga de contradições fundamentais - representa um mecanismo de dominação, calcado em um discurso compartimentado, onde sua expressão máxima é a presença do especialista. Ele produz avanços qualitativos na vida humana, mas também produz a fragmentação entre os saberes e entre o homem e os saberes, e expressa o saber operacional, quantificável, ritualizado em signos e códigos, incapaz de refletir sobre o que não se circunscreve ao seu campo específico de trabalho nem mesmo sobre sua especialidade - como se isso fosse produzido por um desdobramento interno à própria ciência. Portanto, não é algo de caráter neutro, apontando 
para a existência e concretização de fins específicos. A configuração da sociedade, sobretudo a partir do final do século XIX, pode ser abalizada em termos de um desenvolvimento técnico compulsivo, de produção e consumo em larga escala - e por que não patológico - que, em verdade, obnubila a concreta autonomia e emancipação do ser humano. É necessário imprimir à moderna racionalidade científica uma dimensão cujo substrato pode ser dado pela reflexão crítica de base filosófica.

As análises empreendidas têm logrado proporcionar, não apenas para o campo educacional, mas também para outras áreas, um debate amplo e polissêmico, movido para além das dicotomias clássicas, pois a dicotomização na/ e da atividade de pesquisa tende a empobrecê-la, consider ando que a espessura da realidade transborda às estruturas conceituais e teóricas criadas por meio do pensamento mutilante. Entretanto, a dialética a revitaliza no esforço de se reconstruir sua unidade por meio das relações de complementaridade entre objeto/sujeito; imaginação/razão; teoria/prática; universal/singular. O método dialético abriga, a um só tempo, a identidade perene de cada objeto e sua diversidade perante os demais, valendo-se de uma base filosófica constituída de frações e sínteses. Este é o ponto fundante que lhe confere um estatuto epistemológico, considerando que "todo conhecimento comporta o risco do erro e da ilusão" (Morin, 2000, p.19).

A interpretação, entendida como síntese final e provisória, deve superar as dicotomias micro/macro; objetividade/subjetividade; quantitativo/ qualitativo. É uma forma de apropriação do mundo, abarcando a dimensão subjetiva e o sentido objetivo, pois: “Conhecer é conhecer objetos que se integram na relação entre o homem e o mundo, ou entre o homem e a natureza, relação que se estabelece graças à atividade prática do homem" (Vásquez, 1968, p.153). O empreendimento humano torna a realidade cognoscível.

A pesquisa imaginativa é o processo de objetivação da realidade e da práxis do pesquisador que, também, se constitui produto de sua própria atividade. A objetivação funda a postura científica que, embora não reproduza o real - e nem seja um reflexo fiel dele - porque não se presta a isso, busca sempre sua aproximação. A pesquisa imaginativa é um modo de conhecimento, reflexão e clarificação conceitual que implica a descoberta de novos campos e fenômenos. Trata-se de potencializar o elemento criativo na pesquisa, em toda sua extensão e complexidade, a fim de conceber saberes que possam ir além da imediaticidade do objeto, já que o “[...] pensamento é criação, não vontade de verdade" (Deleuze \& Guatarri, 1996, p.73). E quais os efeitos de uma ciência compartimentada no processo de pesquisa? A atividade investigativa esvazia-se, pois se volta fundamentalmente à localização e resolução de problemas particulares, sem um enlaçamento mais amplo com o campo onde se situa o estudo particular. Assiste-se a uma gama de pesquisas desse tipo nas ciências humanas, sobretudo, operando uma transformação substancial do pesquisador como resolvedor de problemas, afastando-o de todo o encadeamento interno ao processo de construção do conhecimento científico e do desenvolvimento de sua lógica histórica concreta. 


\section{Referências}

ADORNO, T.W.; HORKHEIMER, M. Sociologica. Madrid: Taurus, 1979.

BOURDIEU, P.; CHAMBOREDON, J.C.; PASSERON, J.C. A construção do objeto. In: A

profissão de sociólogo: preliminares epistemológicas. 3.ed. Petrópolis: Vozes, 2002. p.45-72.

BUBER, M. Le problème de l' homme. Paris: Aubier, 1962.

CASTRO, C.M. A prática da pesquisa. São Paulo: McGraw-Hill, 1978.

CHAUI, M. Introdução à história da filosofia: dos pré-socráticos a Aristóteles. São Paulo: Brasiliense, 1994.

CHIZZOTTI, A. Pesquisa em Ciências Humanas e Sociais. São Paulo: Cortez, 2000.

DELEUZE, G.; GUATARRI, F. O que é Filosofia? Rio de Janeiro: Ed. 34, 1996.

DEMO, P. Metodologia científica em Ciências Sociais. 3.ed. São Paulo: Atlas, 1981.

. Pesquisa: princípio científico e educativo. 7.ed. São Paulo: Cortez, 2000.

DESCARTES, R. Discurso do método. 3.ed. São Paulo: Abril Cultural, 1983. p.25-71. (Os Pensadores)

DILTHEY, W. Introducción a las Ciencias del Espíritu. Madri: Revista de Occidente, 1956.

DURKHEIM, E. A educação como processo socializador: função homogeneizadora e função diferenciadora. In: FORACCHI, M.; PEREIRA, L. (Orgs.). Educação e Sociedade. São Paulo: Ed. Nacional, 1969. p.34-78.

As regras do método sociológico e outros textos. 2.ed. São Paulo: Abril Cultural, 1983. (Os Pensadores)

DUSSEL, E. 1492: o encobrimento do outro. Petrópolis: Vozes, 1993.

GOLDMANN, L. Ciências Humanas e Filosofia - que é Sociologia? São Paulo: Difusão Européia do Livro, 1967.

HARDING, S. The science question in feminism. Ithaca: University Press, 1986.

HEISENBERG, W. Ordnung der Wirklichkeit. München: Piper, 1989.

JOJA, A. A lógica dialética. São Paulo: Fulgor, 1965.

LEFORT, C. O nascimento da ideologia e do humanismo. In: As formas da história. São Paulo: Brasiliense, 1979. p.251-94.

LOWY, M. Método dialético e teoria política. 3.ed. Rio de Janeiro: Paz e Terra, 1985.

LUKÁCS, G. Existencialismo ou marxismo? São Paulo: Senzala, 1967.

. História e consciência de classe. Porto: Publicações Escorpião, 1974.

MANGUEL, A. Lendo imagens. São Paulo: Companhia das Letras, 2001.

MORIN, E. Os sete saberes necessários à educação do futuro. 2.ed. São Paulo: Cortez, 2000.

Ciência com consciência. 5.ed. Rio de Janeiro: Bertrand Brasil, 2001.

MOSCOVICI, S. Prefácio. In: GUARESCHI, P.; JOVCHELOVICH, S. (Orgs.). Textos em representações sociais. 8.ed. Petrópolis: Vozes, 1995. p.7-16.

MOYA, C. Sociólogos y sociologia. Madrid: Ediciones Castilha, 1980.

OMNĖS, R. Filosofia da ciência contemporânea. São Paulo: Ed. Unesp, 1996.

PATY, M. Ciência - aquele obscuro objeto de pensamento e uso. Tempo Soc., v.11, n.1, p.63-73, 1999. 
MORAES, R.V.

PESSANHA, J. Filosofia e modernidade: racionalidade, imaginação e ética. Porto Alegre: Artes Médicas, 1993.

SAID, E. Orientalismo: o Oriente como invenção do Ocidente. São Paulo: Companhia das Letras, 1990.

SANTOS, B.S. Pela mão de Alice: o social e o político na pós-modernidade. 5.ed. São Paulo: Cortez, 1999.

SCHNITMAN, D.F. (Org.). Novos paradigmas, cultura e subjetividade. Porto Alegre: Artes Médicas, 1996.

VÁSQUEZ, A.S. Filosofia da praxis. Rio de Janeiro: Paz e Terra, 1968.

WAN-HO, M. A morte do determinismo. Folha de S. Paulo. São Paulo, 25 mar. 2001. Caderno MAIS!, p.16-8.

WEBER, M. A "objetividade" do conhecimento na ciência social e na política social. In: Metodologia das Ciências Sociais. 2.ed. São Paulo: Cortez, 1992. p.107-54.

MORAES, R.V. Por una investigación imaginativa en la formación del joven investigador. Interface - Comunic., Saúde, Educ., v.11, n.21, p.105-18, jan/abr 2007.

Se discuten algunas cuestiones concernientes a la ciencia y sus desdoblamientos internos, bajo el modo de producción capitalista, teniendo como eje central una racionalidad orientada fundamentalmente por combinar la mundialización capitalista con la monopolización de los conocimientos técnicos y científicos. El hombre, en cuanto objeto de sí mismo, es incapaz de reflexionar sobre sí propio y sobre su práctica, aunque haya desarrollado mecanismos refinados para conocer la realidad. El debate abre perspectivas para pensar determinados aspectos de la formación del joven investigador, en el área de ciencias humanas, como la ausencia de una discusión acerca de los límites y alcances del ejercicio científico. En ese sentido, se sugiere la idea de investigación imaginativa, como un modo de conocimiento, reflexión y clarificación teórica.

PALABRAS CLAVE: ciencia. construcción del conocimiento. investigación imaginativa. investigadores. dominios científicos. 